\title{
Optimization and comparative analysis of PID and FOPID controller for BLDC motor
}

\author{
P. Vimala1, C. R. Balamurugan ${ }^{2}$, A. Subramanian ${ }^{3}$, T. Vishwanath ${ }^{4}$ \\ ${ }_{1,3,4}$ Department of EEE, IFET College of Engineering, Villupuram, India \\ ${ }^{2}$ Department of EEE, Karpagam College of Engineering, Coimbatore, India
}

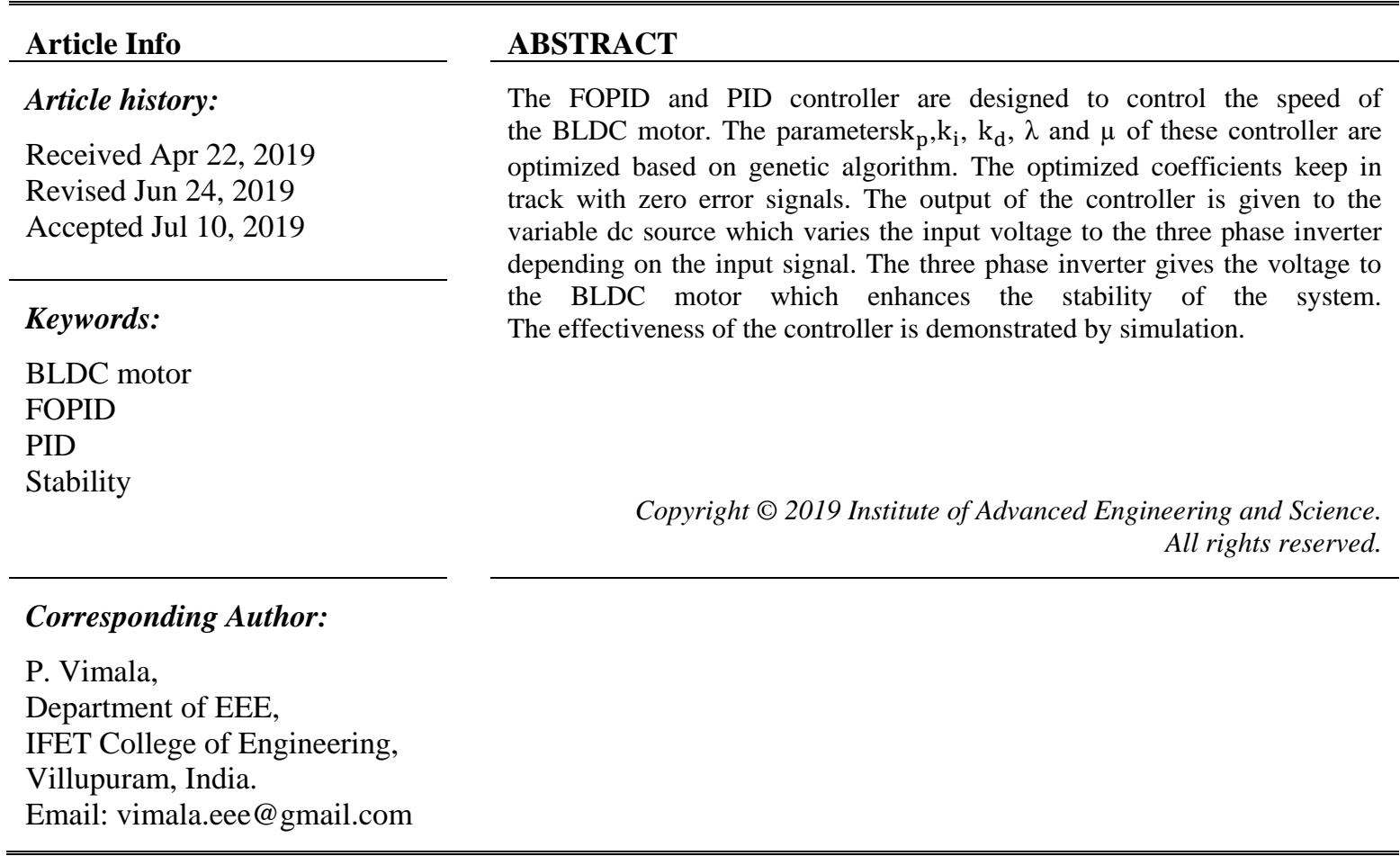

\section{INTRODUCTION}

Brushless de motor has windings in the stator and permanent magnet in the rotor. As it does not have brushes and commutator the efficiency of the motor increases with decrease in the ohmic loses. Brushless dc motor are available in single phase, two and three phase configuration. But three phase configuration are commonly used. Generally, Hall Effect sensors are used to sense the position of the rotor. But in this project the rotor position is determined from excitation current and voltage across the stator windings. The BLDC motor requires inverter as there is no brush and commutation arrangement. The inverter uses transistor for low drive application and Thyristor for high power drives. MOSFET/DIODE switches are used in the inverter. The commutation sequence to the MOSFET/DIODE depends on the rotor position. BLDC motor require less maintenance, generate less noise, have low inertia, have high efficiency, has long operating life.

The controller is used to improve the dynamic response of the system. The PID and FOPID controller parameters are tuned by genetic algorithm [1], more optimization techniques are used to tune the coefficients ofFOPID and PID controller [2]. In this paper the process to control is speed of the BLDC motor. The BLDC motor is modeled [3,4]. The FOPID controller transfer function is formed by using FOMCON toolbox $[5,6]$. The genetic algorithm optimization to tune PID and FOPID is done by suing optimization toolbox. 


\section{SPEED CONTROL OF BLDC MOTOR}

The block diagram for speed control of BLDC motor is shown in Figure 1. The rotor position and speed of the BLDC motor is computed from the voltage and current supplied to the stator windings of BLDC motor. Each phase winding is excited in a sequence to run the BLDC motor. The phase winding of the BLDC motor is excited in a sequence by sequence commutation of the MOSFET/DIODE in the inverter [7, 8].

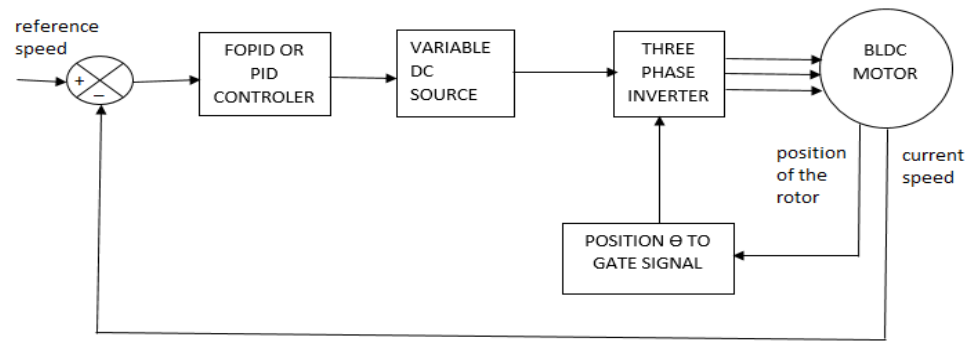

Figure 1. Block diagram of the proposed system

That switching sequence is given to the inverter from position to gate signal block as shown in Figure 1. The speed of the BLDC motor is directly proportional to the voltage. Therefore, to control the speed of the BLDC motor, the input voltage must be controlled. The speed computed is compared with the reference speed by the comparator and the error signal is obtained. The error signal is given as input to the controller. The output of the controller is control signal. This control signal is given as input to the variable DC source. There by the input DC voltage is controlled based on the BLDC motor speed.

\subsection{PID controller:}

The PID controller consists of the proportional, integral and derivative controller. He proportional controller gives proportional response of the input error value. The integral controller is proportional to magnitude and the duration of the error. It improves the settling point and eliminates steady state error. The integral term gives response which also depends on the sum of previous error values. The sum of the previous error value is multiplied with the gain ki. The derivative control gives the slope of the error for specified duration and multiples it with the gain $\mathrm{kd}$. The sum of this proportional, integral and derivative control gives the PID controller. The control signal of PID controller in time domain.

$$
u(t)=k_{p} e(t)+k_{i} \int_{0}^{t} e(t) d t+k_{d} \frac{d e(t)}{d t}
$$

Taking Laplace transform of above equation, the transfer function of PID controller is given by,

$$
G_{c}(S)=\frac{U(S)}{E(S)}=k_{p}+\frac{k_{i}}{s}+k_{d} s
$$

Where, $\mathrm{k}_{\mathrm{p}}$ is proportional gain, $\mathrm{k}_{\mathrm{i}}$ is integral gain, $\mathrm{k}_{\mathrm{d}}$ is derivative gain, $\mathrm{e}(\mathrm{t})$ is an error signal.

The block diagram of PID controller is shown in Figure 2. The parameter $\mathrm{k}_{\mathrm{p}}, \mathrm{k}_{\mathrm{i}}, \mathrm{k}_{\mathrm{d}}$ have to be tuned by using genetic algorithm. The PID controller can implement in MATLAB/Simulink by PID block available in continuous time toolbox.

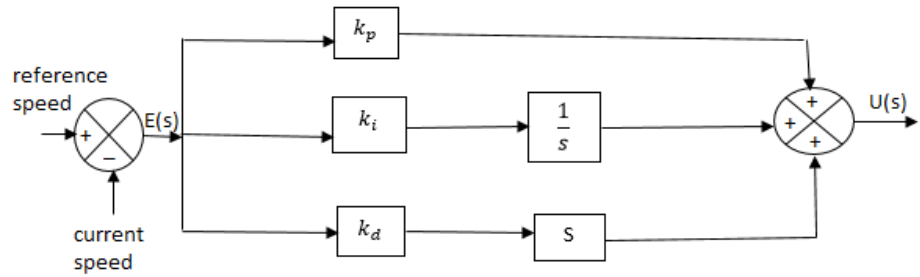

Figure 2. Block diagram of PID controller 


\subsection{FOPID controller}

Fractional order PID controller is commonly in the form $\mathrm{PI}^{\lambda} \mathrm{D}^{\mu}$. In this the integrator and differentiator is in the order of $\lambda$ and $\mu$ respectively [9]. The time domain representation of FOPID control signal is,

$$
u(t)=k_{p} e(t)+k_{i} D^{-\lambda} e(t)+k_{d} D^{\mu} e(t)
$$

Where, $\mathrm{D}^{-\lambda}$ - Fractional order integrator, $\mathrm{D}^{\mu}$ - Fractional order differentiator. Taking Laplace transform for above equation, the transfer function of FOPID controller is given by,

$$
G_{c}(S)=\frac{U(S)}{E(S)}=k_{p}+\frac{k_{i}}{s^{\lambda}}+k_{d} S^{\mu}
$$

Where, $\lambda$ - Order of integrator, $\mu$ - Order of differentiator. The block diagram of FOPID controller is shown in Figure 3.

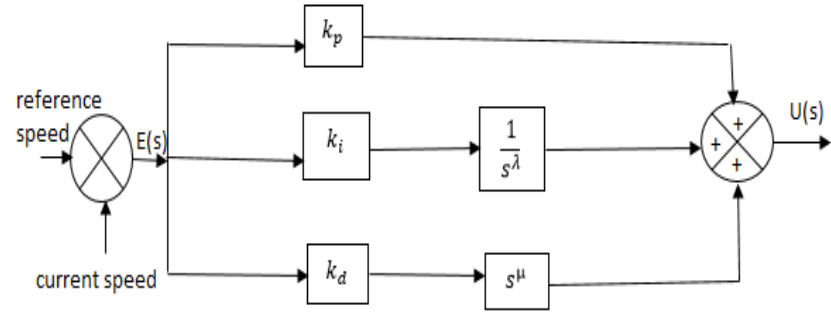

Figure 3. Block diagram of FOPID controller

\section{DESIGN OF BLDC MOTOR}

The rotor and shaft of the BLDC motor is assumed to be rigid [10]. The mode is assumed as having viscous friction model. Therefore the friction torque is proportional to the shaft angular velocity. Based on Newton second law and Kirchhoff's voltage law, three phase star connected BLDC motor can be described by following (1-4).

$$
\begin{aligned}
& T_{e}=b \Theta_{m}+J \frac{d^{2} \theta_{m}}{d t^{2}}+T_{L} \\
& V_{a b}=R\left(i_{a}-i_{b}\right)+L \frac{d\left(i_{a}-i_{b}\right)}{d t}+e_{a}-e_{b} \\
& V_{b c}=R\left(i_{b}-i_{c}\right)+L \frac{d\left(i_{b}-i_{c}\right)}{d t}+e_{b}-e_{c} \\
& V_{c a}=R\left(i_{c}-i_{a}\right)+L \frac{d\left(i_{c}-i_{a}\right)}{d t}+e_{c}-e_{a}
\end{aligned}
$$

Where $\mathrm{T}_{\mathrm{e}}, \Theta_{\mathrm{m}}, \mathrm{b}, \mathrm{J}, \mathrm{T}_{\mathrm{L}}, \mathrm{V}, \mathrm{R}, \mathrm{L}, \mathrm{I}$, e are electrical torque, mechanical rotational speed, viscous friction constant, the rotor inertia, mechanical load torque, phase to phase voltage, phase resistance, phase current, phase inductance and phase back emf respectively. The voltage and current equation is given by (5-6),

$$
\begin{aligned}
& V_{a b}+V_{b c}+V_{c a}=0 \\
& I_{a b}+I_{b c}+I_{c a}=0
\end{aligned}
$$

To simplify the modeling, only two voltage equation are need, they are (7-8).

$$
2 V_{a b}+V_{b c}=3 R i_{a}+3 L \frac{d i_{a}}{d t}+2 e_{a}-e_{b}-e_{c}
$$




$$
-V_{a b}+V_{b c}=3 R i_{b}+3 L \frac{d i_{b}}{d t}+2 e_{b}-e_{a}-e_{c}
$$

The torque generated by the BLDC motor is given by (9),

$$
T_{e}=\left(e_{a} i_{a}+e_{b} i_{b}+e_{c} i_{c}\right) / \frac{d \theta_{m}}{d t}
$$

The trapezoidal back emf can be written as (10-12) :

$$
\begin{aligned}
& e_{a}=\frac{k_{e}}{2} \frac{d \theta_{m}}{d t} \operatorname{Tr} a\left(\Theta_{e}\right) \\
& e_{b}=\frac{k_{e}}{2} \frac{d \Theta_{m}}{d t} \operatorname{Tr} a\left(\Theta_{e}-\frac{2 \pi}{3}\right) \\
& e_{c}=\frac{k_{e}}{2} \frac{d \theta_{m}}{d t} \operatorname{Tr} a\left(\theta_{e}-\frac{4 \pi}{3}\right)
\end{aligned}
$$

Where $k_{e}, \theta_{e}$ is the back emf constant and electrical angle respectively.

$$
\Theta_{e}=p \Theta_{m}
$$

$\operatorname{Tra}\left(\theta_{\mathrm{e}}\right)$ is the trapezoidal waveform unction and one period of the function can be described as follow (13):

$$
\operatorname{Tra}\left(\theta_{e}\right)=\left\{\begin{array}{lc}
1, & 0 \leq \theta_{e}<\frac{2 \pi}{3} \\
1-\frac{6}{\pi}\left(\theta_{e}-\frac{2 \pi}{3}\right), & \frac{2 \pi}{3} \leq \theta_{e}<\pi \\
-1+\frac{6}{\pi}\left(\theta_{e}-\frac{5 \pi}{3}\right), & \frac{5 \pi}{3} \leq \theta_{e}<2 \pi
\end{array}\right.
$$

Substituting (10-12) in (9) we torque as follows (14):

$$
T_{e}=\frac{k_{e}}{2}\left[\operatorname{Tr} a\left(\Theta_{e}\right) i_{a}+\operatorname{Tr} a\left(\Theta_{e}-\frac{2 \pi}{3}\right) i_{b}+\operatorname{Tr} a\left(\Theta_{e}-\frac{4 \pi}{3}\right) i_{c}\right]
$$

The angle of the rotor and speed of the rotor is related as follows (15-16):

$$
\begin{aligned}
& w_{e}=\frac{d \theta_{m}}{d t} \\
& w_{e}=p w_{m}
\end{aligned}
$$

Where, $w_{e}$ - Electrical speed, $w_{m}$ - Mechanical speed. From the equation (1) and (15), we get the speed equation as (17):

$$
w_{m}=\frac{T_{e}-T_{L}-k_{f} w_{m}}{J s}
$$

From (7), The current $i_{a}$ is given as (18):

$$
i_{a}=\frac{2 V_{a b}+V_{b c}-2 e_{a}+e_{b}+e_{c}-3 R i_{a}}{3 L s}
$$

From (8), as

$$
i_{b}=\frac{-V_{a b}+V_{b c}-2 e_{a}+e_{b}+e_{c}-3 R i_{a}}{3 L s}
$$

From (6), The current $i_{c}$ is given as (20):

$$
i_{c}=-i_{a}-i_{b}
$$




\section{INVERTER TOPOLOGY}

The inverter used here is a three phase inverter. It consist of three leg and six MOSFET/DIODE. It is implemented by using universal bridge available in toolbox. The gate signal in this universal bridge decides the MOSFET commutation. The inverter is shown in Figure 4 And for Circuit diagram of de motor is shown in Figure 5.

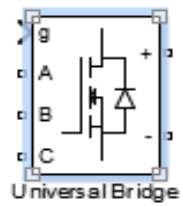

Figure 4. Three phase MOSFET/DIODE inverter

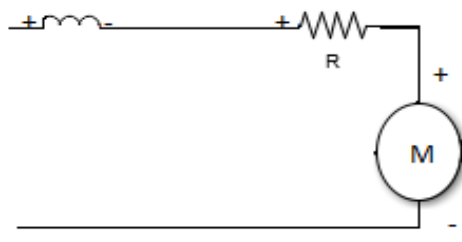

Figure 5. Circuit diagram of DC motor

\section{SYSTEM MODELLING}

Transfer function of BLDC motor: Using Kirchhoff's voltage law (21),

$$
V_{s}=R i+L \frac{d i}{d t}+e
$$

Where $V_{s}, \mathrm{R}, \mathrm{I}, \mathrm{L}$, e are the source voltage, resistance in ohm, current to the motor, inductance of the coil, back emf respectively. The torque of the dc motor from second law of motion is given by (22),

$$
T_{e}=k_{f} w_{m}+J \frac{d w_{m}}{d t}+T_{L}
$$

Where $T_{e}, k_{f}, \mathrm{~J}, w_{m}, T_{L}$ are the electrical torque, the friction constant, the rotor inertia the angular velocity and the supposed mechanical load respectively. The electrical torque and the back emf could be written as,

$$
\mathrm{e}=k_{e} w_{m} \text { and } T_{e}=k_{t} w_{m}
$$

Where $k_{e}$ is back emf constant and $k_{t}$ is torque constant. From equation (21) and (22). The transfer function for $\mathrm{dc}$ motor is given as (23):

$$
G(s)=\frac{w_{m}}{V_{s}}=\frac{k_{t}}{s^{2} J L+\left(R J+k_{f} L\right) s+k_{f} R+k_{e} k_{t}}
$$

Considering the following assumption,

- The friction constant is small $\left(k_{f}=0\right)$

$-\quad R J \gg k_{f} L$

$-\quad k_{e} k_{t} \gg k_{f} R$

And multiplying by $\frac{R}{k_{e} k_{t}} \times \frac{1}{R}$ in (23). The transfer function of dc motor is given as (24):

$$
G(s)=\frac{\frac{1}{k_{e}}}{\tau_{m} \tau_{e} s^{2}+\tau_{m} s+1}
$$

Where mechanical time constant $\tau_{m}=\frac{R J}{k_{e} k_{t}}$

Electrical time constant $\tau_{e}=\frac{L}{R}$

But for the BLDC motor

$$
\begin{gathered}
\tau_{m}=\sum \frac{R J}{k_{e} k_{t}} \\
\tau_{e}=\sum \frac{L}{R}
\end{gathered}
$$


Therefore, since there is a symmetrical arrangement and a three phase the mechanical and electrical constant become (25),

$$
\begin{aligned}
& \tau_{m}=\frac{3 R J}{k_{e} k_{t}} \\
& \tau_{e}=\frac{L}{3 R}
\end{aligned}
$$

Considering the phase effect (26),

$$
\tau_{m}=\frac{3 R_{\varphi} J}{\frac{k_{e(L-L)}}{\sqrt{3}} k_{t}}
$$

Where, $k_{e}=\frac{k_{e_{(L-L)}}}{\sqrt{3}}$. From the MAXON EC 45 FLAT BLDC motor datasheet, the value of phase resistance, phase inductance, rotor inertia and mechanical time constant are shown in Table 1.

\begin{tabular}{cccc} 
Table 1. MAXON EC 45 FLAT BLDC motor datasheet \\
\hline Parameter & Symbol & Value & Unit \\
\hline Phase resistance & $R_{\varphi}$ & 1.2 & Ohm \\
Phase inductance & $\mathrm{L}$ & 0.560 & $\mathrm{Mh}$ \\
Rotor inertia & $\mathrm{J}$ & $92.5 \times 10^{-6}$ & $\mathrm{gcm}^{2}$ \\
$\begin{array}{c}\text { Mechanical time } \\
\text { constant }\end{array}$ & $\tau_{m}$ & 17.1 & $\mathrm{Ms}$ \\
\hline
\end{tabular}

Substituting the above values in (25),

$$
\tau_{e}=155.56 \times 10^{-3}
$$

From (26), $k_{e}=0.076 \frac{v-\operatorname{secs}}{\mathrm{rad}}$,

Substituting the values of $\tau_{m}, \tau_{e}, k_{e}$ in (24) we get the transfer function of BLDC motor as (27):

$$
G_{1}(s)=\frac{13.11}{2.66 \times 10^{-6} s^{2}+0.0171 s+1}
$$

Transfer function of inverter: The transfer function of the inverter is given as (28):

$$
G_{2}(s)=\frac{k_{\text {in }}}{1+s T_{\text {in }}}
$$

Delay time $T_{\text {in }}=0.004 \mathrm{sec}$

$$
\text { Gain }_{\text {in }}=\frac{2}{\pi} \frac{V_{D C}}{V_{c m}}=0.65 \times \frac{200}{20}=6.36
$$

Therefore (29),

$G_{2}(s)=\frac{6.36}{1+0.004 s}$

Finally, the transfer function of the system is given by (30),

$$
\begin{aligned}
& G(s)=G_{1}(s) \times G_{2}(s) \\
& G(s)=\frac{83.38}{1.064 \times 10^{-08} s^{3}+7.106 \times 10^{-05} s^{2}+0.0211 s+1}
\end{aligned}
$$

The parameters are tuned for this system. 


\section{GENETIC ALGORITHM}

Genetic algorithm is an optimization technique. This technique is used to tune the parameter of PID and FOPID controller [11, 12]. The flowchart of the genetic algorithm is shown in Figure 6.

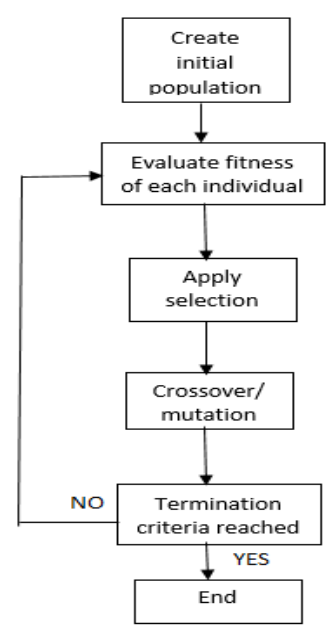

Figure 6. Flowchart of genetic algorithm

It is an iterative process with the population in each iteration called a generation. First the initial population is generated. The population may range from hundred to thousand. From the population the fitness solution to each individual is chosen by objective function. In the selection process the portion of the existing population is selected. In the crossover/mutation, a new generation is generated. Finally, it checks whether it meet the criteria. If it meets the criteria it gets terminate otherwise the iteration repeats.

\subsection{Optimization of the PID and FOPID using genetic algorithm}

The genetic algorithm can be implemented by using optimization toolbox. In FOPID tuning the parameter $k_{p}, k_{i}, k_{d}, \lambda$, and $\mu$ should be tuned to the proposed system [13]. The fitness function should be called as @(x) fun name(x). The lower and upper limit of the cost function is shown in the Table 2. The parameter of genetic algorithm is chosen as in Table 3.

Table 2. Limit of FOPID parameter

\begin{tabular}{ccc}
\hline FOPID parameter & Lower limit & Upper limit \\
\hline $\boldsymbol{K}_{\boldsymbol{P}}$ & 0 & 2 \\
$\boldsymbol{K}_{\boldsymbol{i}}$ & 0 & 2 \\
$\Lambda$ & 0 & 1 \\
$\boldsymbol{K}_{\boldsymbol{d}}$ & 0 & 2 \\
$\mu$ & 0 & 1 \\
\hline
\end{tabular}

Table 3. Criteria of genetic algorithm

\begin{tabular}{cc}
\hline Population & 200 \\
\hline Initial population & 10 \\
Selection & Stochastic uniform \\
Mutation & Constraint dependent \\
Crossover & Constraint dependent \\
\hline
\end{tabular}

In PID tuning, $k_{p}, k_{i}, k_{d}$ are the cost function. The limit of PID controller is chosen as in Table 4. Similarly by choosing criteria in optimization toolbox the parameter are tunes as shown in Table 5 . The graphical representation is given as shown in Figure 7. 
Table 4. Limit of PID controller

\begin{tabular}{ccc}
\hline PID parameters & Lower limit & Upper limit \\
\hline $\mathbf{K}_{\mathbf{P}}$ & 0 & 2 \\
$\mathbf{K}_{\mathbf{i}}$ & 0 & 2 \\
$\mathbf{K}_{\mathbf{d}}$ & 0 & 2 \\
\hline
\end{tabular}

Table 5. Tuned value of parameter of controller

\begin{tabular}{cccccc}
\hline & $\boldsymbol{K}_{\boldsymbol{P}}$ & $\boldsymbol{K}_{\boldsymbol{i}}$ & $\boldsymbol{K}_{\boldsymbol{d}}$ & $\Lambda$ & $\mu$ \\
\hline PID & 1.98 & 1.782 & 1.869 & 1 & 1 \\
FOPID & 1.904 & 1.7818 & 1.7061 & 0.1835 & 0.2217 \\
\hline
\end{tabular}

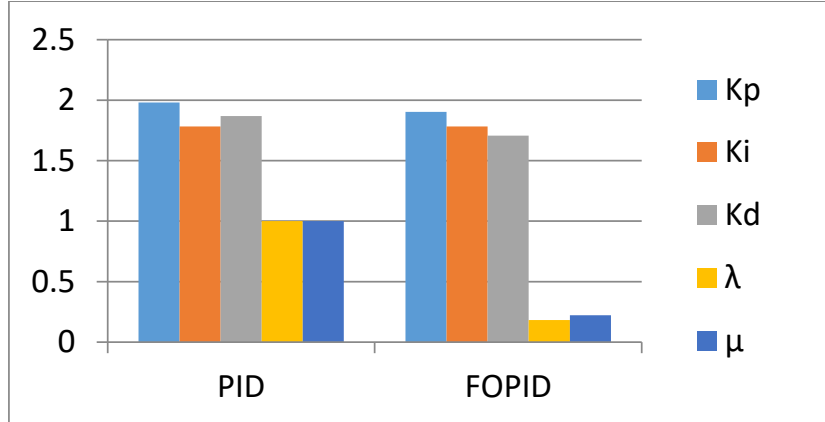

Figure 7. Comparison plot

The graph generated while tuning the parameter of FOPID controller is shown in Figure 8 and for PID controller is shown in Figure 9.

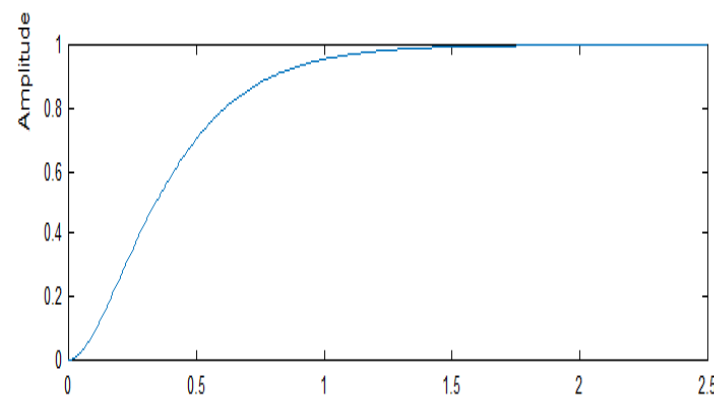

Figure 8. FOPID step response by genetic algorithm

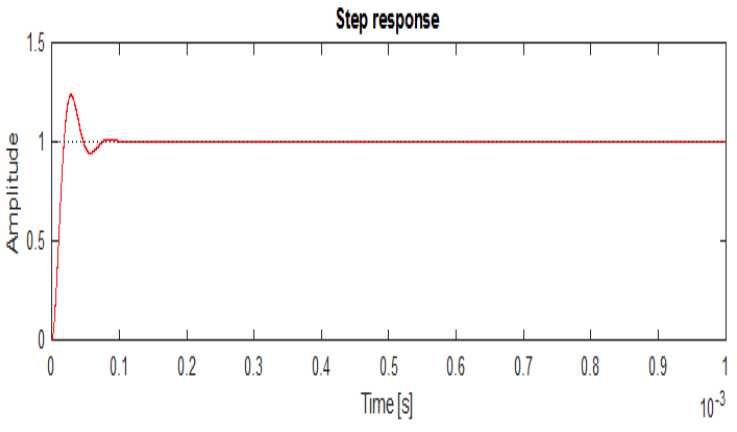

Figure 9. PID step response by genetic algorithm

\section{SIMULATION AND RESULT}

The simulation model of the speed control of BLDC motor is shown in Figure 10. The PID controller is implemented by using PID block available in MATLAB. The transfer function of FOPID is generated by using FOMCON toolbox. The output speed response for PID controller is shown in Figure 10.

An external disturbance is applied to the BLDC motor at 0.5 second. The PID controller controls the input voltage and the BLDC motor reaches the steady state at 8.5 second. Thus the settling time of the BLDC motor using PID controller is 8 second. The output speed response of the system due to FOPID controller is shown in Figure 11.

An external disturbance is applied to the BLDC motor at 0.5 second. The FOPID controller controls the input voltage and the BLDC motor reaches the steady state at 1.3 second. Thus the settling time of the BLDC motor using FOPID controller is 0.8 second. Therefore the settling time of the speed due to the FOPID controller is 10.5 times faster than the PID controller. Comparison of PID and FOPID speed response is shown in Figure 12. 


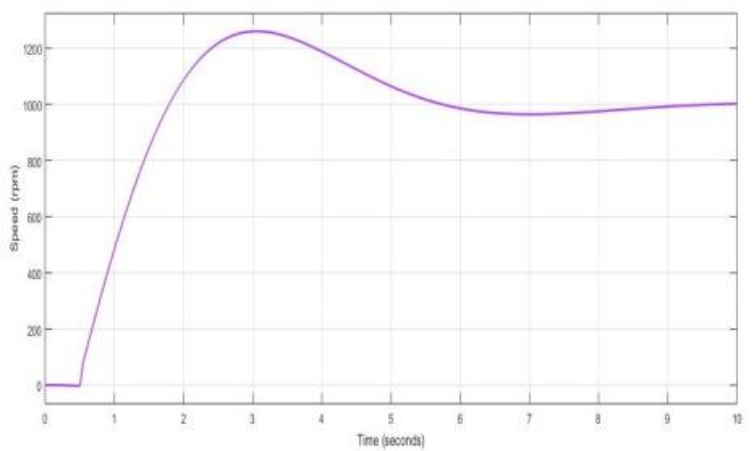

Figure 10. Speed response due to PID controller

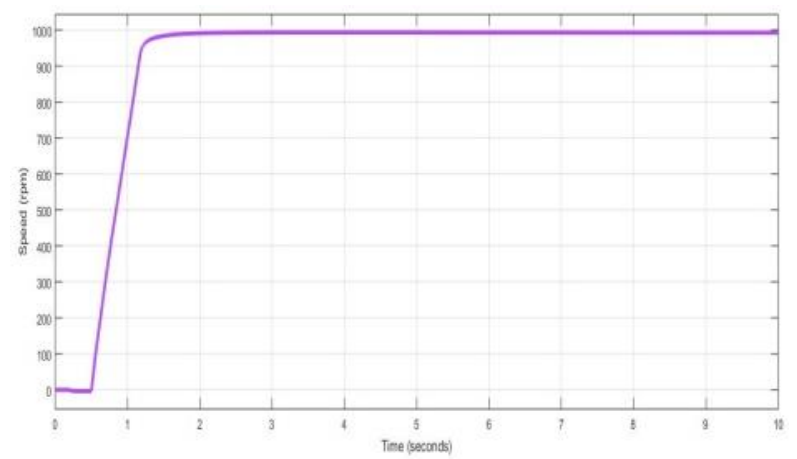

Figure 11. Speed response due to FOPID controller

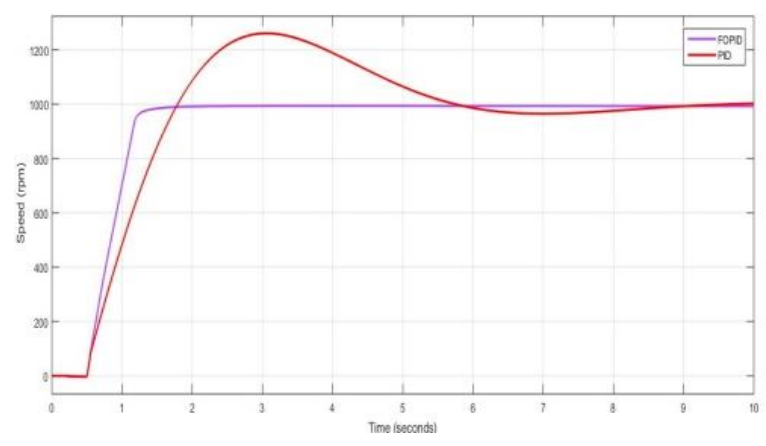

Figure 12. Comparison of PID and FOPID speed response

In this section, it is explained the results of research and at the same time is given the comprehensive discussion. Results can be presented in Figures, graphs, Tables and others that make the reader understand easily $[14,4]$. The discussion can be made in several sub-chapters.

\section{CONCLUSION}

The FOPID controller enhances the dynamic response of the BLDC motor compared to the conventional PID controller. The settling time of the speed response is very fast when we use FOPID controller. So the performance of the FOPID based speed controller is better and efficient. Stability and robustness of the BLDC motor can be improved. So this proposed controller can be extended to other industrial control system.

\section{REFERENCES}

[1] S. W. Khubalkar, A. S. Chopade, A. S. Junghare and M. V. Aware, "Design and tuning of fractional order PID controller for speed control of permanent magnet brushless DC motor," 2016 IEEE First International Conference on Control, Measurement and Instrumentation (CMI), Kolkata, 2016.

[2] Xiaotian Li, "Model-Based Design of Brushless DC Motor Control and Motion Control Modelling for RoboCup SSL Robots," Technology and Communication, 2015.

[3] Venu Kishore kadiyala, Ravi Kumar jatoth, sake pothalaiah, "Design and implementation of fractional order PID controller for Aerofin control system,”696978-1-4244-5612-3/09/\$26.00 c @ IEEE, 2009.

[4] Deep Mukherjee, KshitijRastogi, "A Performance Analysis Between IOPID and FOPID Controller on A Coupled Tank," International Conference on Inventive Systems and Control, 2017.

[5] Man. K. F, S. Tang, and S. Kwong, "Genetic Algorithms: Concepts and Applications," IEEE Transactions On Industrial Electronics, Vol. 43, No. 5, October 519, 1996.

[6] Narmada. K and M. Arounassalame, "Design and performance evaluation of Fractional ORDER controller for Brushless DC Motor," International Journal on Electrical Engineering and Informatics, Volume 6, Number 3, September, 2014.

[7] Aleksei Tepljakov, Eduard Petlenkov and Juri Belikov, "FOMCON: Fractional-Order Modeling and Control Toolbox for MATLAB," MIXDES 2011, 18th International Conference "Mixed Design of Integrated Circuits and Systems", June 16-18, Gliwice, Poland, 2011. 
[8] Sundaravadivu. K, B. Arun, K. Saravanan, "Design of Fractional Order PID Controller for Liquid Level Control of Spherical Tank," IEEE International Conference on Control System, Computing and Engineering, 2011.

[9] Olundayo john oguntoyinbo, "PID control of Brushless dc motor and ROBOT trajectory planning and simulink with MATLAB/SIMULINK," Technology and Communication, 2009.

[10] Ameer L. Saleh, Adel A. Obed, "Speed Control of Brushless DC Motor based on Fractional Order PID Controller," International Journal of Computer Applications (0975 - 8887) Volume 95- No.4, 2014.

[11] WojciechGiernacki, "Near to Optimal Design of $\mathbf{P I}^{\lambda} \mathbf{D}^{\mu}$ Fractional-Order Speed Controller (FOPID) For Multirotor Motor Rotor Simplified Model,” 2016 International Conference on Unmanned Aircraft Systems, 2016.

[12] Zhe Yan, Kai Li, Changqi Song, ling He, Yingyan Li, "Tuning and Application of Fractional Order PID Controllers," 2nd International Conference on Measurement, Information and Control, 2013.

[13] Vishal Mehra, Smriti Srivastava, and PragyaVarshney, "Fractional-Order PID Controller Design for Speed Control of DC Motor," Third International Conference on Emerging Trends in Engineering and Technology, 2010.

[14] W. Lin and Z. Chongquan, "Design of optimal fractional-order PID controllers using particle swarm optimization algorithm for DC motor system," 2015 IEEE Advanced Information Technology, Electronic and Automation Control Conference (IAEAC), Chongqing, 2015, pp. 175-179. 